\title{
Response to "Oral health in the elderly patient and its impact on general well-being: a nonsystematic review" paper
}

This article was published in the following Dove Press journal:

Clinical Interventions in Aging

2 May 2015

Number of times this article has been viewed

\section{Małgorzata Muc-Wierzgoń Teresa Kokot \\ Ewa Nowakowska-Zajdel Adam Błażelonis \\ Edyta Fatyga}

Department of Internal Medicine, Silesian Medical University, Bytom, Poland
Correspondence: Małgorzata MucWierzgoń

Department of Internal Medicine, Silesian Medical University, st Żeromskiego 7, 4I-902 Bytom, Poland

$\mathrm{Tel} / \mathrm{fax}+483228 \mathrm{l} 2122$

Email mwierzgon@sum.edu.pl

\section{Dear editor}

Gil-Montoya et al has recently published an interesting article in Clinical Interventions in Aging entitled: "Oral health in the elderly patient and its impact on general well-being: a nonsystematic review". ${ }^{1}$ Authors presented a non-systematic review of the published data regarding the oral health status of the elderly and its main repercussions, including its impact on general health and nutrition.

As the authors underline, the risk of cavities, root caries, and more commonly observed tooth sensitivity or dry mouth increases with age. Acute and chronic comorbidities, as well as pharmacologic agents used in the treatment of these diseases show a significant impact on oral health. ${ }^{1,2}$

Poor oral health can affect a person's quality of life. Among those aspects for keeping up good oral health; daily oral hygiene practices, health education, diet type, and proper oral health policy formulation are very important. ${ }^{3}$ Actually, epidemiological research of dental problems indicates that most of the elderly neglect hygiene and oral care - brushing their teeth only once a day or not al all, not flossing daily, not cleaning their tongues, not replacing missing teeth with dentures, and avoiding regular dental checkups. ${ }^{4,5}$ Teeth loss and edentulism may be a possible outcome of such actions particularly in elderly. Some authors propose that edentulism could be a good mortality predictor and others associate it with a substantive quality of life impairment. ${ }^{1}$ While the National Institute of Dental and Craniofacial Research reported that the prevalence of both partial and total tooth loss in seniors has decreased from the early 1970s, seniors over 65 have lost an average of 13 teeth (including wisdom teeth), and $26 \%$ of seniors over 65 have no remaining teeth. ${ }^{6}$ Poor oral hygiene is prevalent among older people all over the world and it is highly associated with oral self-care, behavior, habits, and socio-economic status. ${ }^{2,7}$ Good daily dental hygiene is necessary to maintain good oral health and quality of life in older people. To provide appropriate dental care to the elderly it is also important to promote and provide health education for the elderly, as well as for oral health professionals, public health specialists, and legislators.

In the current demographic and economic perspectives, this is one of the major public health problems of the 21 st century.

\section{Disclosure}

The authors report no conflicts of interest in this work. 


\section{References}

1. Gil-Montoya JA, Ferreira de Mello AL, Barrios R, Gonzalez-Moles MA, Bravo M. Oral health in the elderly patient and its impact on general wellbeing: a nonsystematic review. Clin Interv Aging. 2015;10:461-467.

2. Skorupka W, Żurek K, Kokot T, et al. Assessment of oral hygiene in adults. Cent Eur J Public Health. 2012;20(3):233-236.

3. Steele JG, Sanders AE, Slade GD, et al. How do age and tooth loss affect oral health impacts and quality of life? A study comparing two national samples. Community Dent Oral Epidemiol. 2004;32(2):107-114.

4. Talwar M, Chawla HS. Geriatric dentistry: is rethinking still required to begin undergraduate education? Indian J Dent Res. 2008;19(2): 175-177.
5. Moynihan P, Petersen PE. Diet, nutrition and the prevention of dental diseases. Public Health Nutr. 2004;7(1A):201-226.

6. National Institute of Dental and Craniofacial Research [homepage on the Internet]. Bethesda: Tooth loss in seniors (age 65 and over); 2011. Available from: http://www.nidcr.nih.gov/DataStatistics/FindDataByTopic/ ToothLoss/ToothLossSeniors65andOlder.htm. Accessed March 26, 2015 .

7. Chalmers J, Johnson V, Tang JH, Titler MG. Evidence-based protocol: oral hygiene care for functionally dependent and cognitively impaired older adults. J Gerontol Nurs. 2004;30(11):5-12.

\section{Publish your work in this journal}

Clinical Interventions in Aging is an international, peer-reviewed journal focusing on evidence-based reports on the value or lack thereof of treatments intended to prevent or delay the onset of maladaptive correlates of aging in human beings. This journal is indexed on PubMed Central, MedLine,
CAS, Scopus and the Elsevier Bibliographic databases. The manuscript management system is completely online and includes a very quick and fair peer-review system, which is all easy to use. Visit http://www.dovepress. com/testimonials.php to read real quotes from published authors. 